\title{
THE ROLE OF BEARING AND SCAN MECHANISM LIFE TESTING IN FLIGHT QUALIFICATION OF THE MODIS INSTRUMENT
}

\author{
Steven G. VanDyk', Brian J. Dietz”, Kenneth W. Street ${ }^{+}$, William R. Jones $^{+}$, Jr., Mark J. Jansen ${ }^{+}$, Michael \\ Dube $^{++}$, Rajeev Sharma ${ }^{+++}$, Roamer E. Predmore ${ }^{++}$
}

\begin{abstract}
The Moderate Resolution Imaging Spectroradiometer (MODIS) is an instrument aboard the Terra (EOS AM-1) satellite and has been operating successfully since December 1999. MODIS has been viewing the entire Earth's surface and gathering data to better understand the global dynamics and processes occurring on land, in the oceans, and in the lower atmosphere. All observations are made through an extremely high resolution, optically and mechanically precise, scan mirror motor/encoder assembly. The reliable performance of this assembly depends on two duplex bearing pairs lubricated with Pennzane, a synthetic hydrocarbon, formulated with lead napthanate. This paper describes the results of accelerated and operational life tests. It also describes the post-test analyses of the disassembled bearings. Analyses were performed using micro-Raman, micro-FTIR, X-ray Photoelectron Spectroscopy (XPS), Scanning Electron Microscopy (SEM), and Size Exclusion Chromatography (SEC). In general, the three sets of bearings in each of the test stations were in very good condition after accumulating 68,144 , and 209 million revolutions, respectively. Some of the bearings exhibited lubricant degradation, indicated by viscous lubricant deposits on the cage and raceways.
\end{abstract}

\section{INTRODUCTION}

At the onset of the MODIS development, Pennzane had not been flown on Goddard long life lubricated space mechanisms. Accelerated and real-time life tests were conducted on MODIS scan bearings to demonstrate that Pennzane would successfully lubricate the mechanism for the 5-year $\mathbf{5 3 . 4}$ million cycles) life. Three sets of duplex MODIS bearings were tested at $23^{\circ} \mathrm{C} \& 20.3 \mathrm{RPM}$ for 68 million revolutions (Station IV); at $37^{\circ} \mathrm{C} \& 50 \mathrm{RPM}$ for 144 million revolutions (Station III); and at $45^{\circ} \mathrm{C} \& 72 \mathrm{RPM}$ for 209 million revolutions (Station 11 ). Six months before launch, the $37^{\circ} \mathrm{C}$ accelerated life test was disassembled and two of the three bearing sets were severely worn (Ref. 1). These results raised doubts about flightworthiness of the MODIS instrument. Fortunately, a flight quality scan mechanism had also been tested for 4.7 years at that time. Measurements of torque margins and operating parameters of the engineering model scan mechanism with only a few months of operating time and the life test mechanism showed no torque variation or operating parameter variation. From these measurements, it was concluded that no measurable bearing wear or lubricant degradation occurred during the 4.7 year life test. After almost 5 years of damage free scan mechanism life testing, it was concluded that the TERRAMMODIS instrument was safe to fly. The wisdom of Goddard's requirement for an expensive scan mechanism life test rather than less expensive bearing life testing was demonstrated.

This paper describes the bearing wear and lubricant degradation and distribution after the accelerated bearing life test at $45^{\circ} \mathrm{C}$ and the real time life test at $23^{\circ} \mathrm{C}$. After 68 million cycles (1.3 lives) in the boundary lubrication regime at $23^{\circ} \mathrm{C}$, part of the oil had crept into the support structure. The oil color was dark amber, but in many cases the viscosity was unchanged, all balls, retainers and races were wetted and contained oil meniscuses, and little wear was observed on the balls or races. After 209 million revolutions ( 3.9 lives) at $45^{\circ} \mathrm{C}$, more oil creeped into the support cups, the oil was black and viscous, all balls, retainers and races were wetted, small meniscuses of oil were at the ball race junctions, and very limited wear was observed on the balls and races. Dark deposits of lead or lead napthanate were not

- Raytheon Systems Company, Santa Barbara Remote Sensing, Santa Barbara, CA

" Moog, Inc., Schaeffer Magnetics Division, Chatsworth, CA

+ NASA Glenn Research Center, Cleveland, $\mathrm{OH}$

+* Nye Lubricants, Inc., New Bedford, MA

++ Goddard Space Flight Center, Greenbelt, MD

Proceedings of the $35^{\text {th }}$ Aerospace Mechanisms Symposium, Ames Research Center, May 9-11, 2001 
visible, indicating the lead napthanate remained dissolved in Pennzane after 209 million revolutions at $45^{\circ} \mathrm{C}$. This formulation of Pennzane performed very well at high temperature and in the boundary lubrication regime. The lubricant and bearing surfaces have been analyzed using micro-Raman, microFTIR, X-ray Photoelectron Spectroscopy (XPS), Scanning Electron Microscopy (SEM) and Size Exclusion Chromatography (SEC) and the results summarized.

Comparison of the bearing wear and the lubricant degradation after life testing at $23^{\circ} \mathrm{C}$ and $45^{\circ} \mathrm{C}$, clearly demonstrated that the severe bearing damage found in the $37^{\circ} \mathrm{C}$ accelerated life test originated from a thermal control failure. This drove the bearing test temperature well above $90^{\circ} \mathrm{C}$, as suggested in the Reference 1.

As with most long-life lubricated mechanisms, lubrication life, bearing precision, and dynamic performance are the critical factors in the operation of the scan motor/encoder. As a first phase of lubricant selection for MODIS, bearings were lubricated with several candidate lubricants, accelerated life tests performed, and results evaluated. A synthetic hydrocarbon, Pennzane SHF-X-2000 with $2.5 \%$ lead napthanate and $0.6 \%$ antioxidant additives, was selected. The second phase of lubricant selection consisted of three lubricant life tests. These results were reported in Ref. 1 and in this paper. The third phase was the successful qualification life test of the scan motor/encoder mechanism.

Three bearing test stations were constructed to evaluate the life of Pennzane lubricant for the MODIS optical scan mechanism. Five-flight quality scan motor/encoder mechanisms were fabricated, assembled and tested. The engineering model was used to develop the optical scanning control system. The second mechanism was used for qualification life testing and has successfully completed that testing. The third mechanism was flown in the MODIS instrument on the TERRA satellite. The fourth mechanism will be flown in the MODIS instrument on the AQUA satellite later this year. The fifth mechanism remains as a spare.

Each scan motor/encoder mechanism contains two duplex bearing pairs driven by a brushless dc-motor. Pennzane SHF-X-2000 is a synthetic hydrocarbon lubricant and was chosen for the bearings and mechanism. To mitigate instrument risk, both accelerated and operational speed life testing were conducted in parallel with the mechanism design and fabrication in order to verify the lubricant life early enough in the program to switch lubricants for MODIS if accelerated testing revealed early anomalies.

\section{ACCELERATED AND REAL-TIME PENNZANE LIFE TEST METHOD}

In each test station, three flight quality, $440 \mathrm{C}$ steel, $66.675 \mathrm{~mm}$ (2.625 inch) outer diameter, $50.800 \mathrm{~mm}(2$ inch) inner diameter, DF duplex pair bearings with a $165 \mathrm{~N}$ (37 pound) preload were used. The bearings, phenolic laminate retainers, and sintered nylon reservoirs were lubricated in accordance with flight requirements. The test station is illustrated as Figure 1. Each bearing pair was contained in its own clamp/housing. The housings also contained lubricant reservoirs. Station II and III housings were fitted with inner and outer race heaters. A strain gauge was mounted on a cantilever beam supporting each bearing enclosure to measure the torque. The inner races of three duplex pairs were driven by a common drive shaft. Instantaneous torque readings were recorded every 15 minutes. The monthly average of these readings was plotted over the life of the test (see Figure 2). One telemetry platinum resistance thermometer (PRT) was mounted to each bearing outer race housing. Two control PRTs (Stations II and III only) were also mounted to each bearing housing (one on the outer race and one for the inner race). All testing was performed under vacuum. Although all the Pennzane lubricant was tested in the boundary lubrication regime, the acceleration factor was established as similar calculated specific film thickness $(\lambda)$ in all three-test stations. This method was used as an arbitrary way of creating an accelerated lubrication life test. Three duplex pairs of bearings were tested in Station II at 72 RPM and $45^{\circ} \mathrm{C}$, in Station III at 50 RPM and $37^{\circ} \mathrm{C}$ and $22^{\circ} \mathrm{C}$ and in Station IV at 20.3 RPM and $23^{\circ} \mathrm{C}$. 


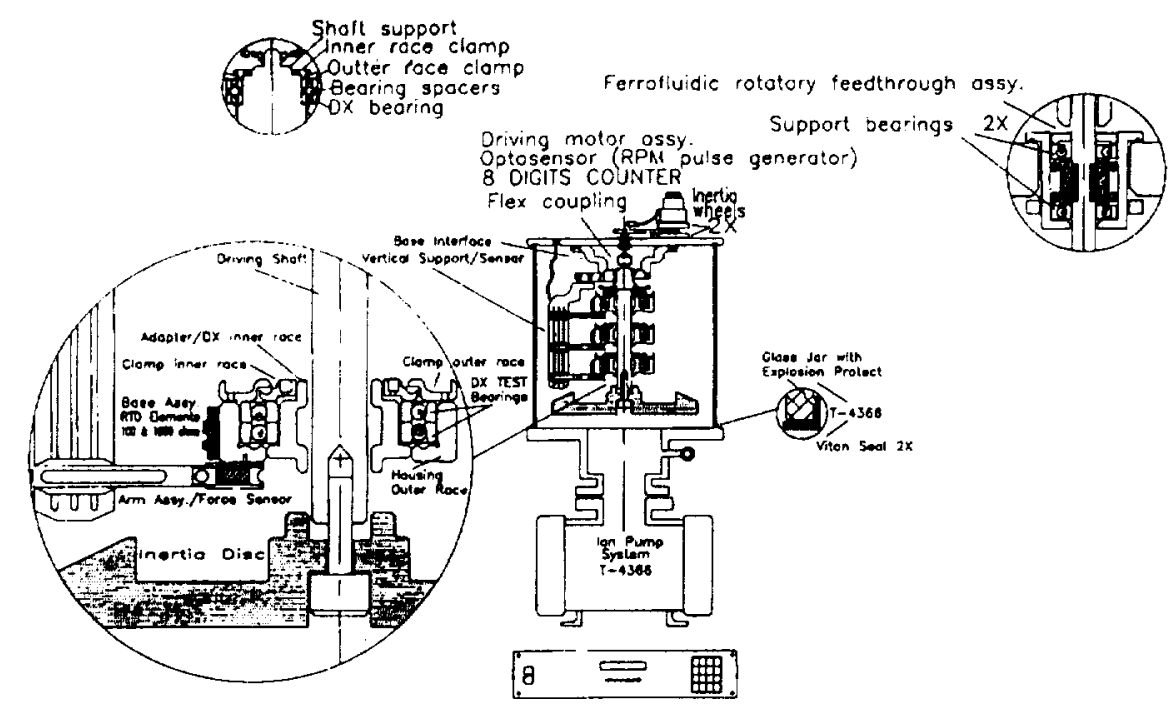

Figure 1 - Test Station

\section{PERFORMANCE EVALUATION OF THE QUALIFICATION LIFE TEST SCAN MECHANISM}

Evaluation of the life test bearings from Station III $\left(37^{\circ} \mathrm{C}\right.$ and $\left.50 \mathrm{RPM}\right)$ had shown severe degradation (Ref. 1). To regain confidence in the MODIS scan mechanism before the launch of TERRA/MODIS, a performance evaluation was conducted on the like-new engineering model (EM) and the qualification life test mechanism after 4.7 years of testing.

The performance of the two test units was measured by evaluating the motor drag torque and phase error signals. At that time (11-1999), the EM scanner had accumulated a few hundred thousand cycles whereas the LTU had completed close to one mission lifetime, about 45.8 million cycles, in vacuum testing.

Both scanners tested had their spin axis vertical with an equivalent inertia disk attached to represent the scanner mirror at the top end of the drive system shaft. The hardware used to record the drag torque and phase error signals was a portable data acquisition system running LabVIEW ${ }^{\mathrm{TM}}$ software and all data was recorded at 250 samples per second.

The steady state drag torques measured on the MODIS EM and LTU scanner units were about $.067 \mathrm{~N}-\mathrm{m}$ (9.4 oz-in) and $.087 \mathrm{~N}-\mathrm{m}(12.2 \mathrm{oz}-\mathrm{in})$ respectively, indicating a beginning-of-life and a end-of-life torque margin of greater than 20 . The more important parameter of margin on phase lock for both units is a healthy 200 percent. Because of the design similarities between the EM and LTU scanner units and the PFM and FM-1 MODIS scanners, it was concluded that the PFM and FM-1 unit MODIS scanners had sufficient margin for a five-year mission life on the Terra and EOS-PM programs.

\section{TEST RESULTS FROM STATION III - 50 RPM at $37^{\circ} \mathrm{C}$}

Bearing life test Station III results were reported at the $34^{\text {th }}$ Aerospace Mechanisms Symposium (Ref. 1). Bearings in this station indicated consistent operation well past 57 million revolutions until a suspected heater malfunction occurred at 88 million cycles (Figure 2). The test continued until 144 million revolutions were achieved, then it was switched off, and disassembled. 


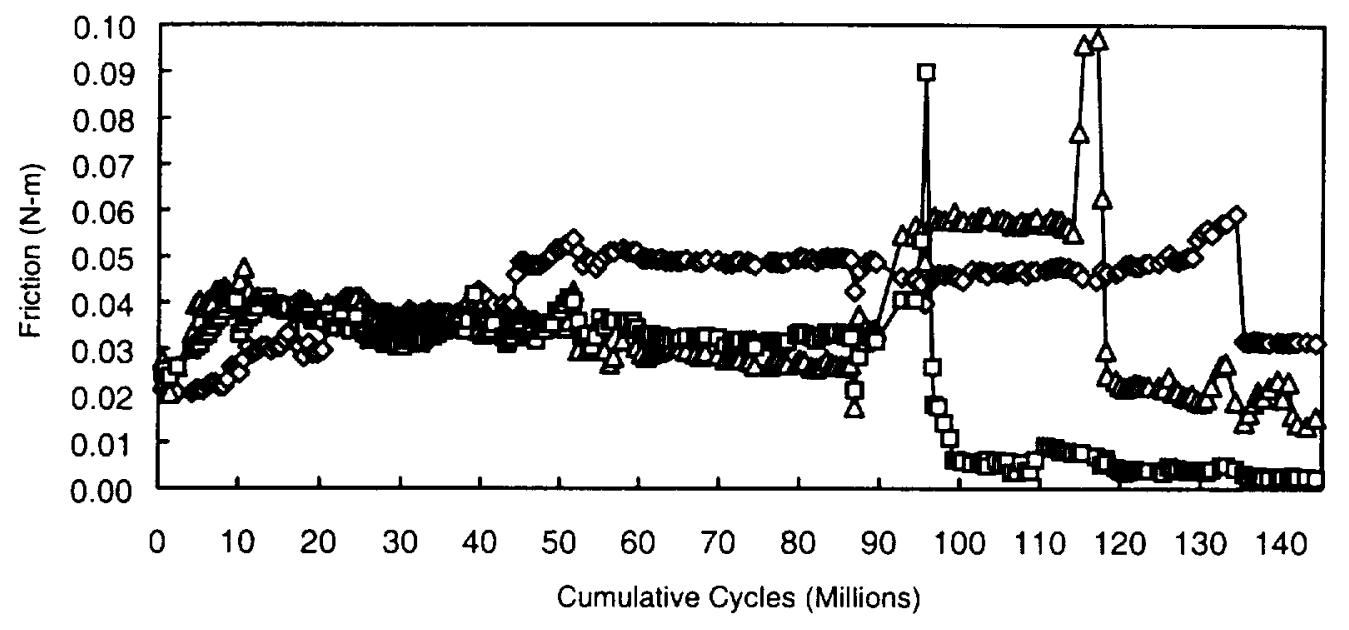

$\rightarrow-$ GAUGE $\| 12 \rightarrow$ GAUGE $\| 13 \rightarrow-$ GAUGE \|\| 1

Figure 2 - Torque vs. revolutions for upper pair bearings (III1), middle bearings (III2), and lower bearings (III3)

\section{PERFORMANCE EVALUATION OF THE STATION II AND IV SCAN MECHANISMS}

These test stations were an accelerated life test running at 72 RPM (Sta. II), and an operational speed station running at approximately 20 RPM (Sta. IV). In order to compensate for the higher speed, heaters were added to the accelerated station to decrease the viscosity of the lubricant. The original plan specified a life test duration of 57 million revolutions. After the bearing life tests successfully achieved the required 57 million revolutions, the test torque data was reviewed and it was concluded that there was no indication of failure so the tests were allowed to continue.

The decision to disassemble these two test stations was finally made after the operational test station surpassed 57 million cycles. At the time of disassembly, the 72 RPM station had accumulated 209 million cycles while the operational speed station had achieved 68 million cycles. Upon disassembly some lubricant discoloration was observed but no visible damage. The bottom bearings of each pair had more lubricant and a stickier feel than the upper bearings. Bearing torque remained well below the operational requirements of the system $\leq 13 \mathrm{~N}-\mathrm{m}(18 \mathrm{oz}$-in) drag torque throughout the life test.

Average torque data is shown in Figure 3 for Station II. Intermittent jittering of the upper bearing pair housing was observed toward the end of testing. Torque characterization with and without visible vibration is shown in Figures 4 and 5 . 
MODIS BEARING SCREENING TEST

STATION \#2

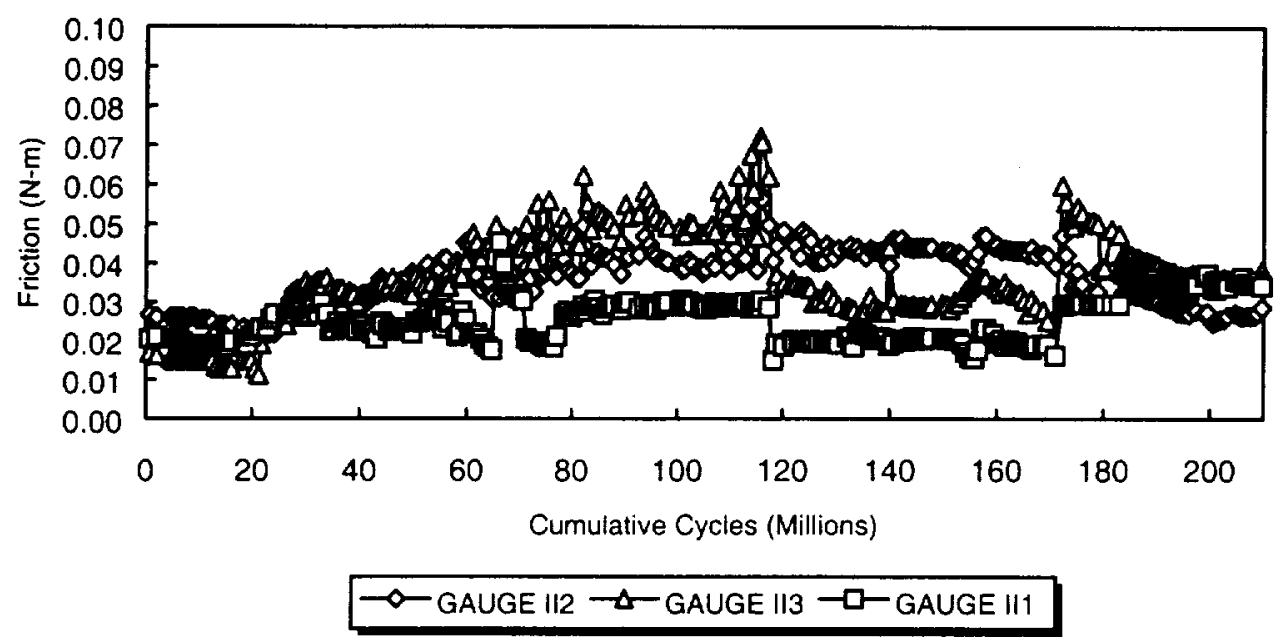

Figure 3 - Torque vs. revolutions for upper pair bearings (II1), middle bearings (II2), and lower bearings (II3)

TORQUE CHARACTERISTICS

GAUGE $\| 1$

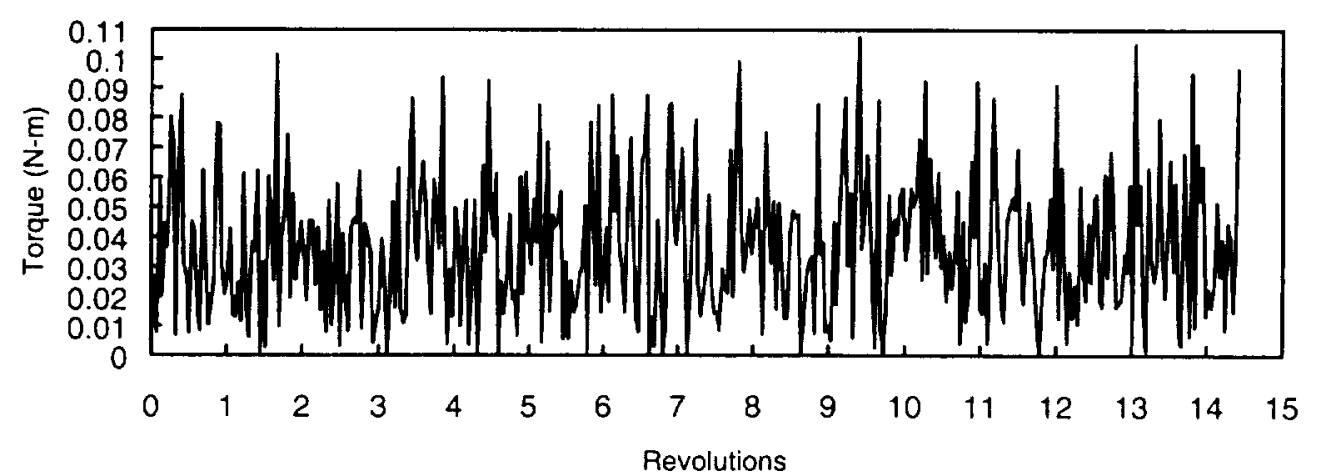

Figure 4 - Torque characterization for Station II upper bearing pair with visible vibration 


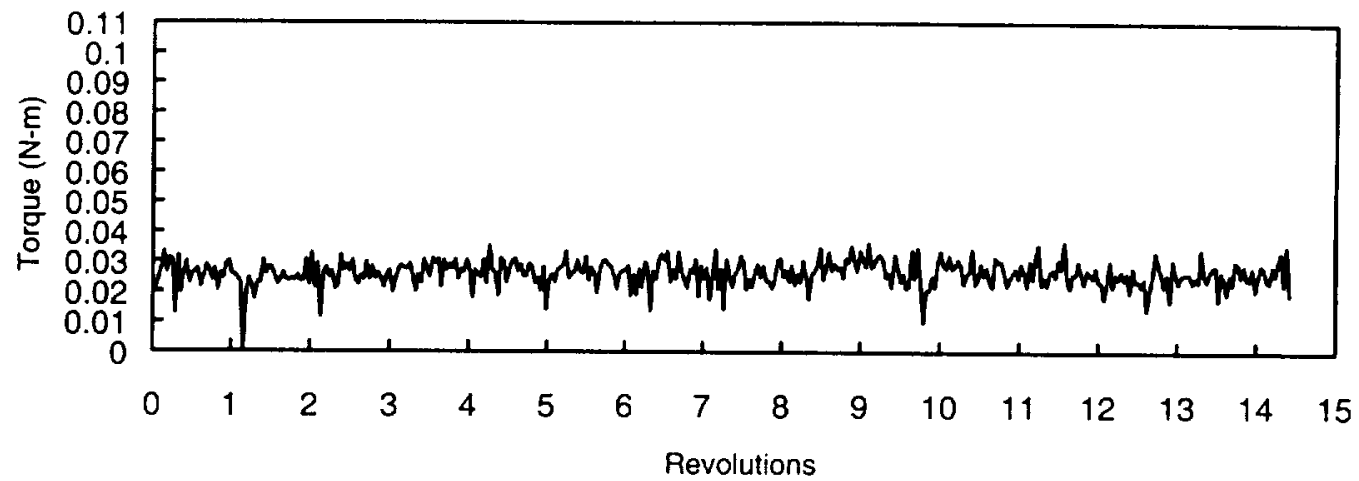

Figure 5 - Torque Characterization for Station II Middle Bearings without Vibration

Station IV operated for 68 million cycles at 20.3 RPM or operational speed. This station operated at room temperature and exhibited vibration that randomly affected the bearings at different times. The vibration was visible and varied with intensity. At times there was no vibration noted on any of the bearings. Torque history for all bearing pairs appears in Figure 6.

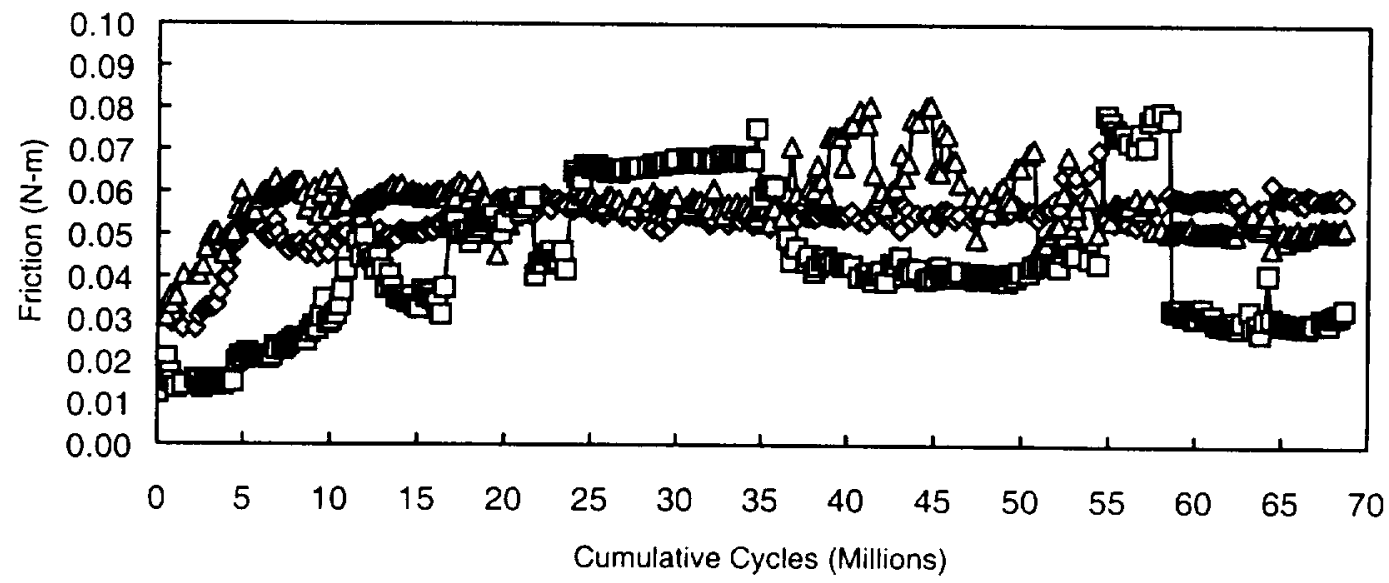

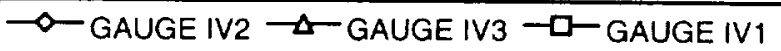

Figure 6 - Torque vs. revolutions for station IV upper pair bearings (IV1), middle bearings (IV2), and lower bearings (IV3) 
Upon completion of 209 and 68 million cycles for Stations $\|$ and IV, respeclively, the stations were disassembled. Photographs were taken throughout the disassembly and inspection process. A test station prior to disassembly is shown in Figure 7. The complete shaft and all bearing components were removed from the test station and transported to a class 100 flow bench in a class 100,000 clean room for further inspection.

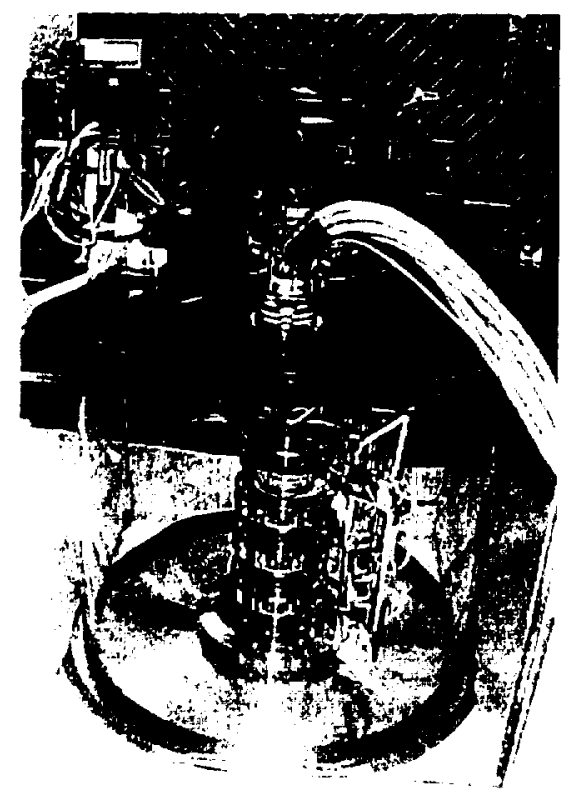

Figure 7 - Test station prior to disassembly

One of the disassembled bearings (4-012) is shown in Figure 8 . Although not easily seen in the macro photograph (Figure 8 ), dark viscous deposits are seen on the cage and raceways. A higher magnification photograph (Figure 9) shows an example of these deposits in a raceway. Two other photographs showing the variation and distribution of lubricant within the raceways appear in Figures 10 (greater amount of lubricant) and Figure11 (lesser amount of lubricant).

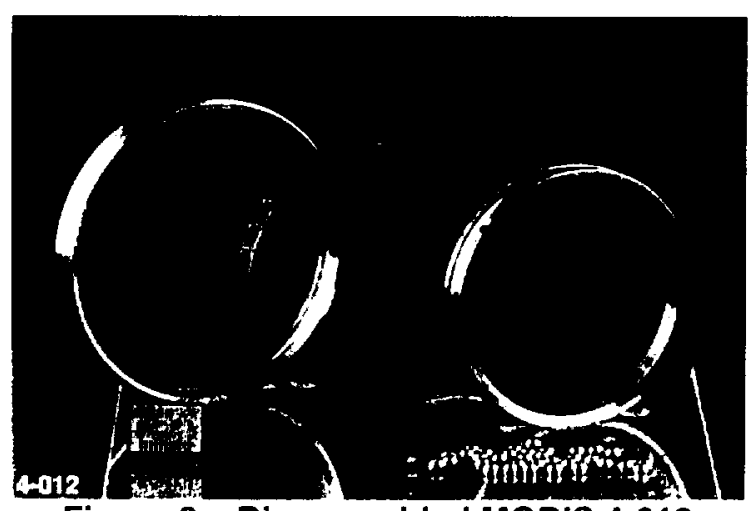

Figure 8 - Disassembled MODIS 4-012 bearing

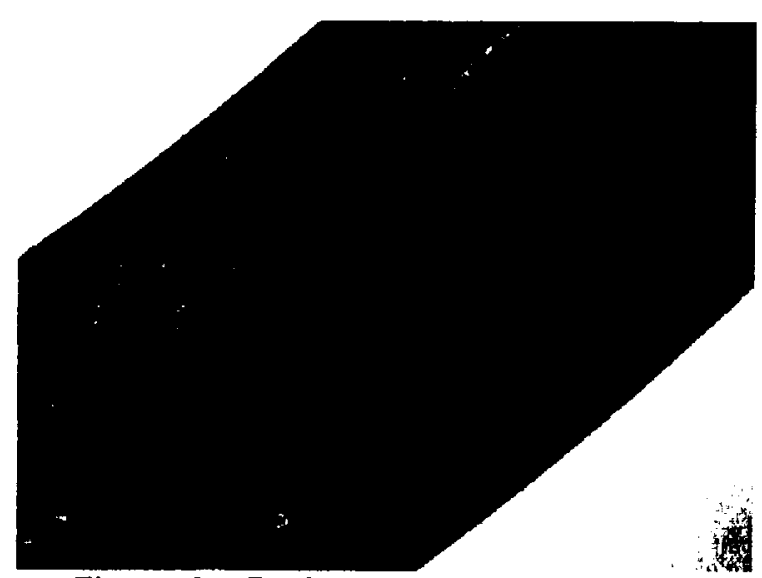

Figure 9-Darkened lubricant deposit 


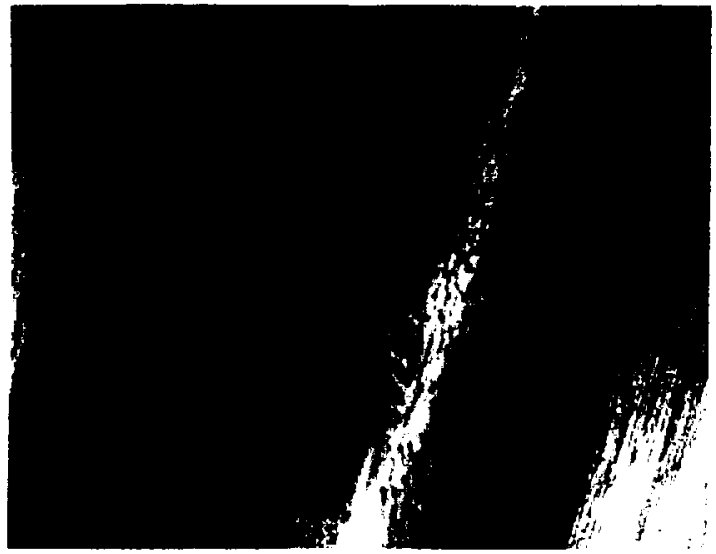

Figure 10 - One bearing from station II with a greater amount of lubricant

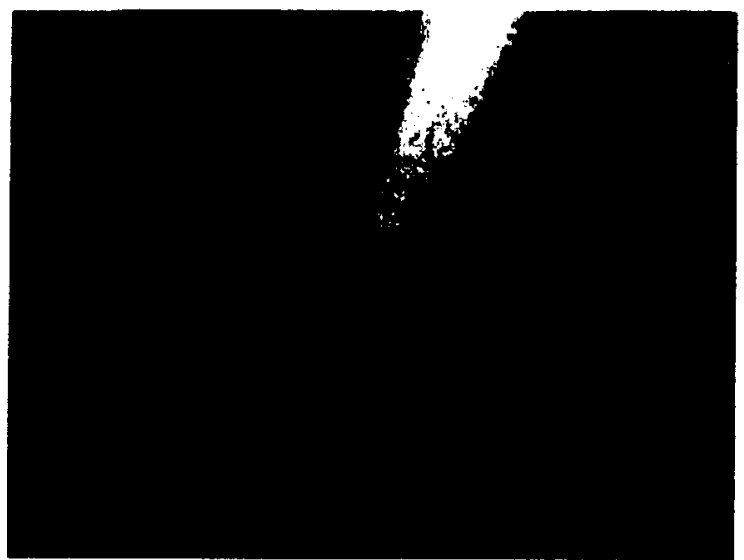

Figure 11 - One bearing from station II with a lesser amount of lubricant

\section{ANALYTICAL RESULTS}

In general, the results showed the balls, retainers, and races were still lubricated and in good condition at the end of test. The top bearing assemblies had less lubricant in both stations II and IV and bottom bearing assemblies had a thicker grease-type residue. There was no sign of dry debris in any of the bearing assemblies. The oil had darkened significantly and was more viscous, almost like honey. Wear paths were seen in the races and on some of the balls. There was no sign of elongation in the retainer pockets. However, some slight metallic debris was observed on some of the retainers. The metallic debris was noticed only on station IV.

Raman and Infrared analyses of the lubricant indicated the standard signature for non-degraded Pennzane. XPS, SEM, and EDAX showed the normal elemental composition for $440 \mathrm{C}$ steel. The most striking demonstration of lubricant degradation was observed in some bearings as a thickened lubricant deposit with almost grease like in consistency. These deposits occurred on both races and on the cage. For the SEC analysis, the cages were all weighted and then extracted using tetrahydrofuran (THF). The solution was then concentrated and injected into a size exclusion chromatograph. An example from bearing 4-012 appears in Figure 12. The detector signal is plotted as a function of molecular weight (MW). Several peaks are evident. The negative peaks at low MW are injection peaks. The peak at 195, which occurs in all samples, is an artifact from a preservative in the mobile phase (THF). The next peak represents the degraded Pennzane compound. The higher MW peak at about 1300 represents the primary Pennzane material as well as a contribution from the lead napthanate. The broad high MW peak centered about 18,000 represents polymerized lubricant. This high MW peak does not occur in unused samples.

The weight of extracted lubricant varied from bearing to bearing with the smallest amount being about 9 $\mathrm{mg}$ from cage $4-015$ and $49 \mathrm{mg}$ from cage 4-002A. This compares to the nominal amount of $75 \mathrm{mg}$ impregnated at build up. In addition, dark residues were observed on cages 4-002A, 4-005A, 4-006A and 4-015A. Photographs for these two cages after THF extraction appear in Figures 13a and $13 \mathrm{~b}$. 


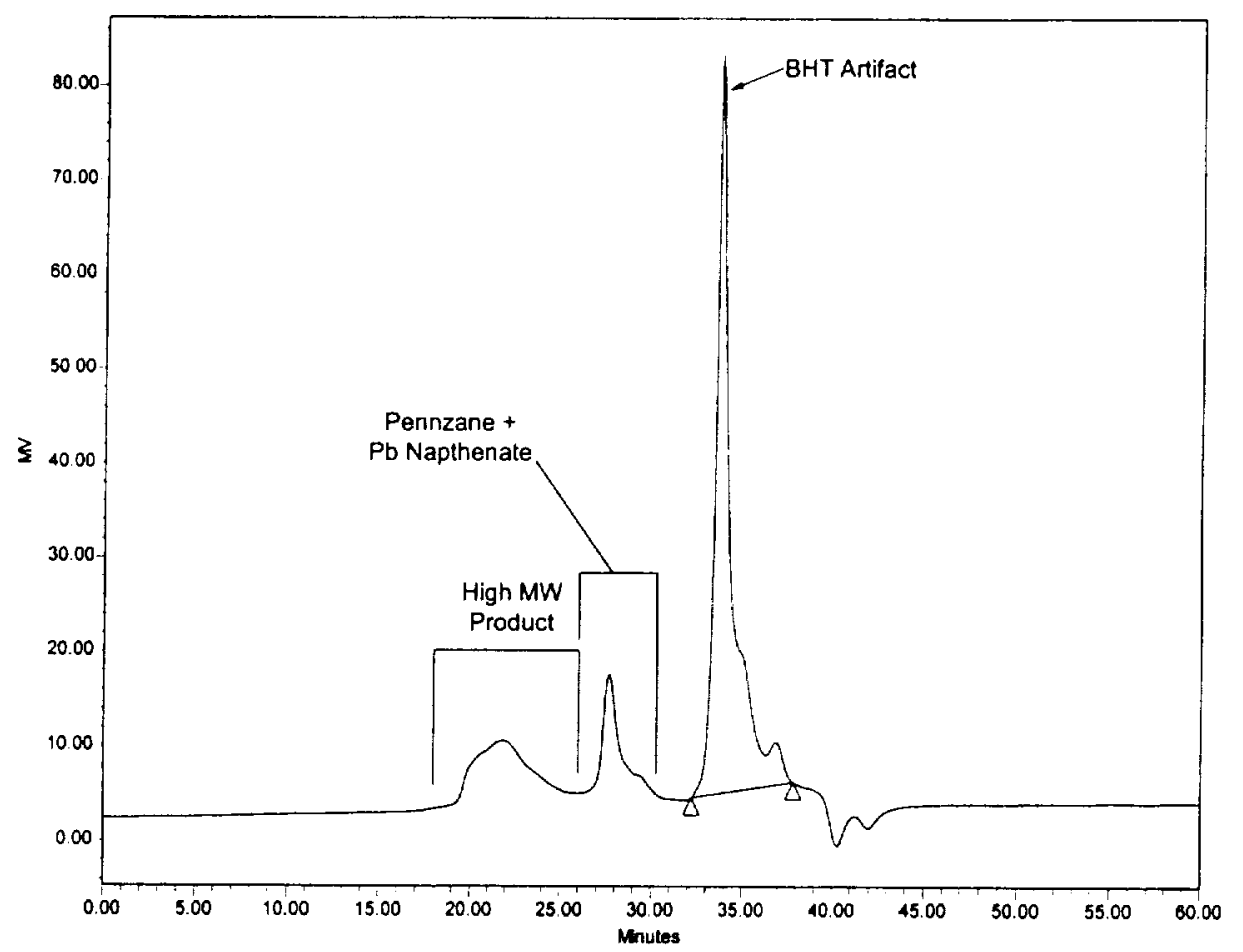

Figure 12 - Size exclusion chromatogram from extracted lubricant from cage 4-012

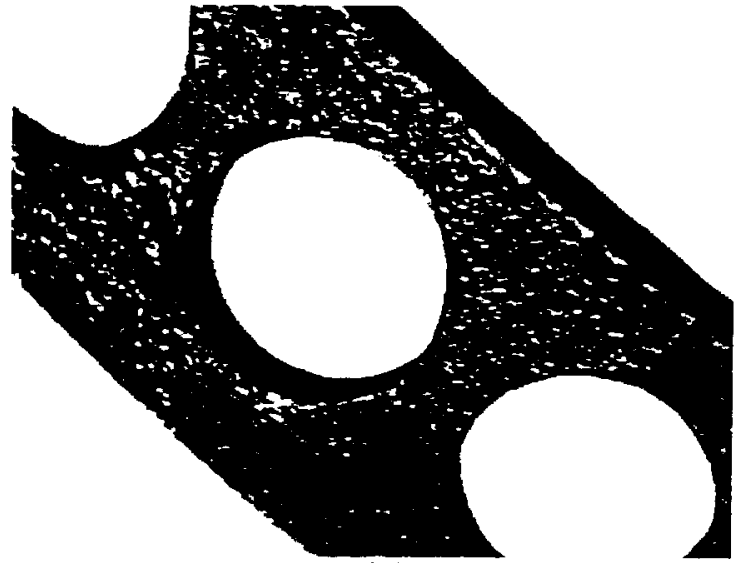

(a)

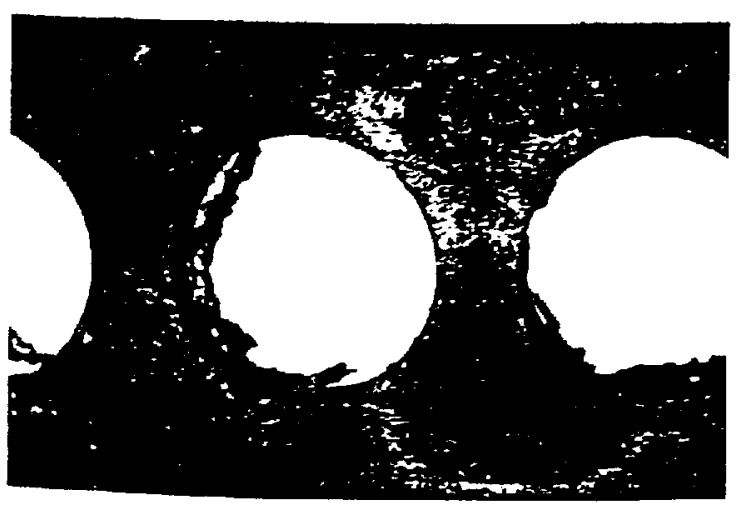

(b)

Figure 13 - Photograph of extracted cage from 4-002A (a) and 4-015A (b) 


\section{PERFORMANCE MEASUREMENT TEST}

Performance tests on the MODIS engineering model (EM) and life test unit (LTU) scanners were made to determine the changes in performance over the expected on-orbit life of the flight unit. The EM and LTU scanners tested were equivalent units to the PFM (in service) and FM-1 scanner, which is scheduled to fly shortly on the EOS-PM (Aqua) program. As a minimum, the scanner drive systems must operate continuously for five years in a constant velocity mode for Earth scanning. The scanner drive system utilized a phase-lock loop control system for maintaining scan rate at the desired value during operation.

Scan motor drag torque and phase error signal performance from both test units was measured, recorded and evaluated. The EM scanner had seen a few hundred thousand rotation cycles whereas the LTU had completed more than one mission lifetime and about 58 million cycles in vacuum testing.

Both scanners tested had their spin axis vertical with an equivalent inertia disk attached to represent the scanner mirror at the top end of the drive system shaft. The hardware used to record the drag torque and phase error signals was a data acquisition system running LabVIEW' ${ }^{\text {mM }}$ software and all data was recorded at 250 samples per second. Figures 14 through 19 document results obtained from the tests performed and are discussed below.

Figure 14 documented the running or steady state drag torque of the EM scanner, which had an average value of $.067 \mathrm{~N}-\mathrm{m}(9.4 \mathrm{oz}-\mathrm{in})$. During this test, the EM unit maintained the required rotation rate of 20.3 rpm with phase-lock control. The beginning-of-life requirement for this value was $.11 \mathrm{~N}$-m (15 oz-in), which was met. The current limit on the PFM and FM-1 MODIS units was about one amp for the flight condition which indicated that the beginning of life torque margin for the scanner was greater than 20 .

Figure 15 documented the measured phase error signal of the EM scanner under turn ON and steady state conditions. When the scanner was initially turned on, there was a large error signal generated between the commanded rate and the actual rate, shown by the indicated spike shortly after turn-on. The phase-lock circuitry was designed to reduce the error between the commanded rate and the actual rate over a given time, therefore the error signal reduced shortly after turn-on to a value of about 1 volt peakto-peak. This was equivalent to a phase error of about 20 micro-radians under steady state scanner rotation.

In Figures 16 and 17 eight attempts to bring the EM scanner out of phase lock by increasing the external drag torque on the drive system were shown. Due to the limitation of the test setup, the external drag was increased manually and the LED on the EM scanner electrical control (METS) box was observed to go out indicating the scanner was out of phase lock. The two figures also showed maximum drag torque where the scanner went out of phase lock. This drag torque compared to the maximum available torque of the scanner motor established the margin that existed for being in phase lock for the EM scanner unit. When the transient drag torque events on Figures 16 and 17, were omitted, retrieving and averaging the maximum drag from the eight attempts indicated that the drag at which point the scanner phase lock was lost occurred at about .71 N-m (100 oz-in). The PFM and FM-1 units had a scanner actuator current limit of about one amp from their power supplies, which indicated a margin on phase lock of about $200 \%$ at the beginning-of-life. This meant that the PFM and FM-1 unit scanners had about three times the available torque capacity in their scanner drive systems to maintain scanner phase lock.

Figure 18 documented the running or steady state drag torque of the LTU scanner which had an average value measured of about $0.086 \mathrm{~N}-\mathrm{m}(12.2 \mathrm{oz}-\mathrm{in})$ after running more than one mission lifetime of 58 million cycles in vacuum. During this test, the LTU unit maintained the required rotation rate of $20.3 \mathrm{rpm}$ with phase-lock control. The measurement indicated that at the end of (one mission) life, the torque margin for the scanner was greater than 20 .

Figure 19 documented the measured phase error signal of the LTU scanner under turn ON and steady state conditions. Similarly as with the EM unit system, when the LTU scanner was initially turned on, there was a large error signal generated between the commanded rate and the actual rate, shown by the indicated spike shortly after turn-on. The phase-lock circuitry was designed to reduce the error between the commanded rate and the actual rate over a given time, therefore there was a reduction in error signal shortly after turn-on to a value of about 0.5 volt peak-to-peak. This was equivalent to a phase error of about 10 micro-radians under LTU scanner steady state rotation. 
Due to the LTU scanner test vacuum apparatus, it was not possible to perform the phase lock tests for comparison to the EM data. Nonetheless, based on phase error and drag torque measurements there was good confidence that the life test unit, after greater than one mission life, had no significant difference in measurable parameters and therefore has good correlation in margin for phase lock equivalent to the EM unit measured data.

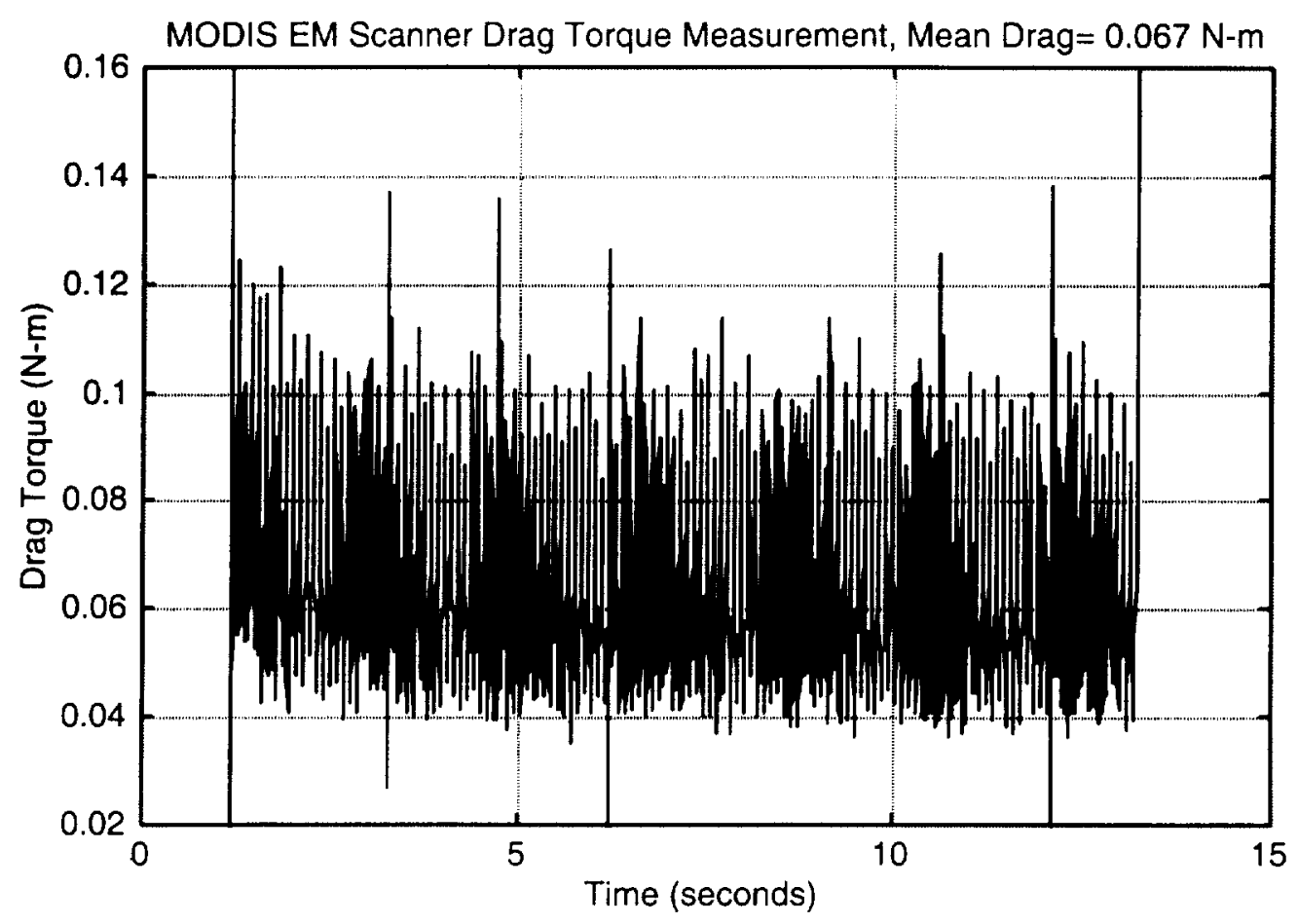

Figure 14 - MODIS EM Scanner Steady State Drag Torque.

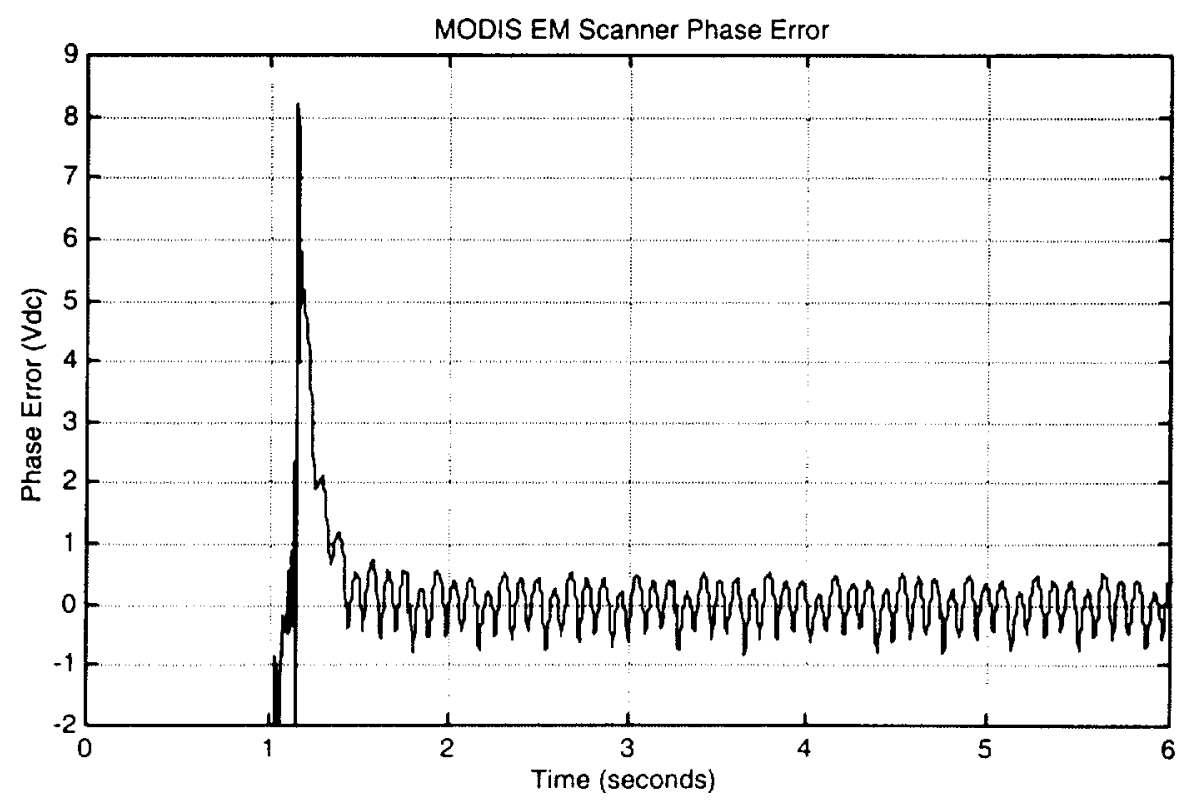

Figure 15 - MODIS EM Scanner Phase Error. 


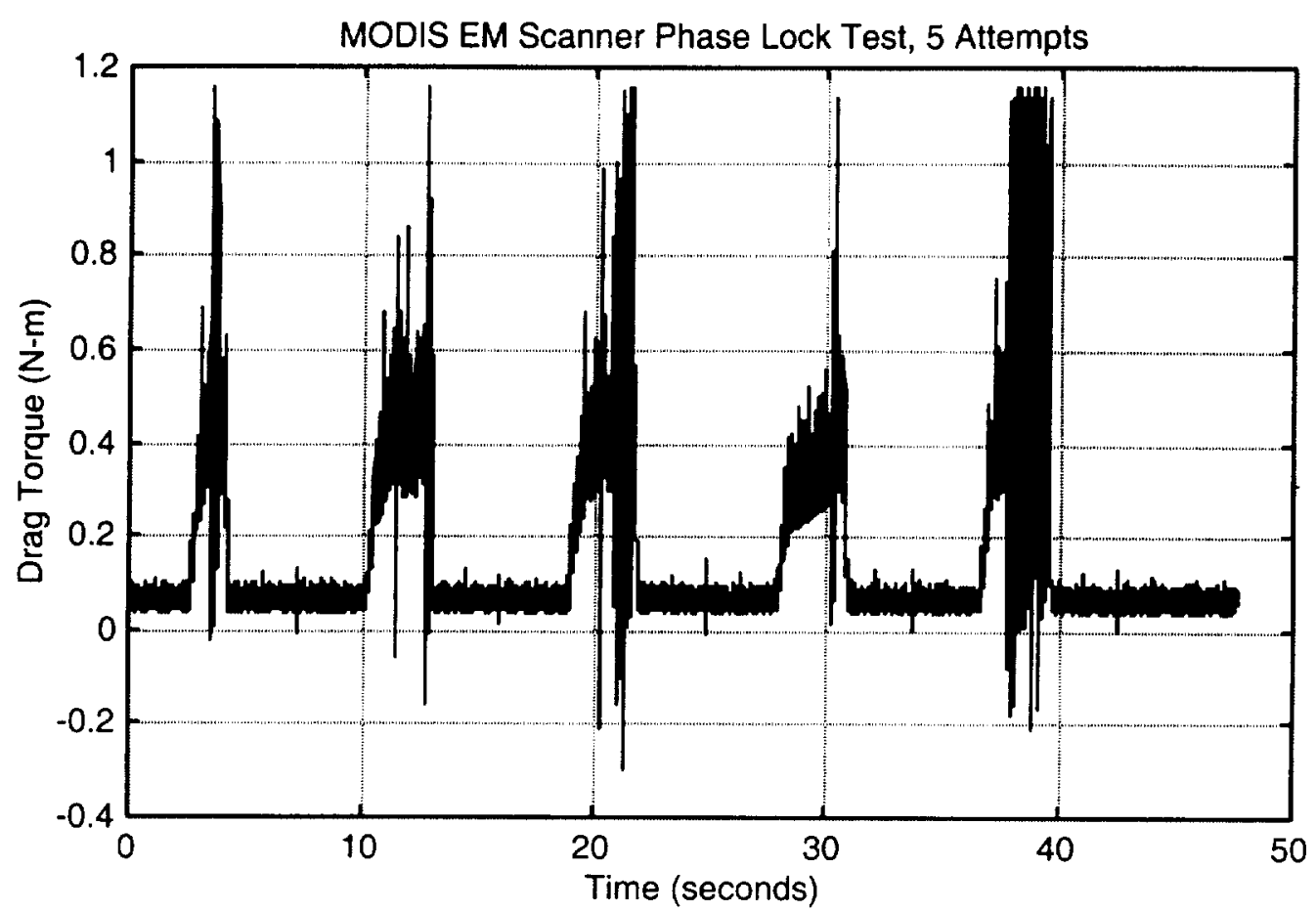

Figure 16 - MODIS EM Scanner Phase Lock Test 1.

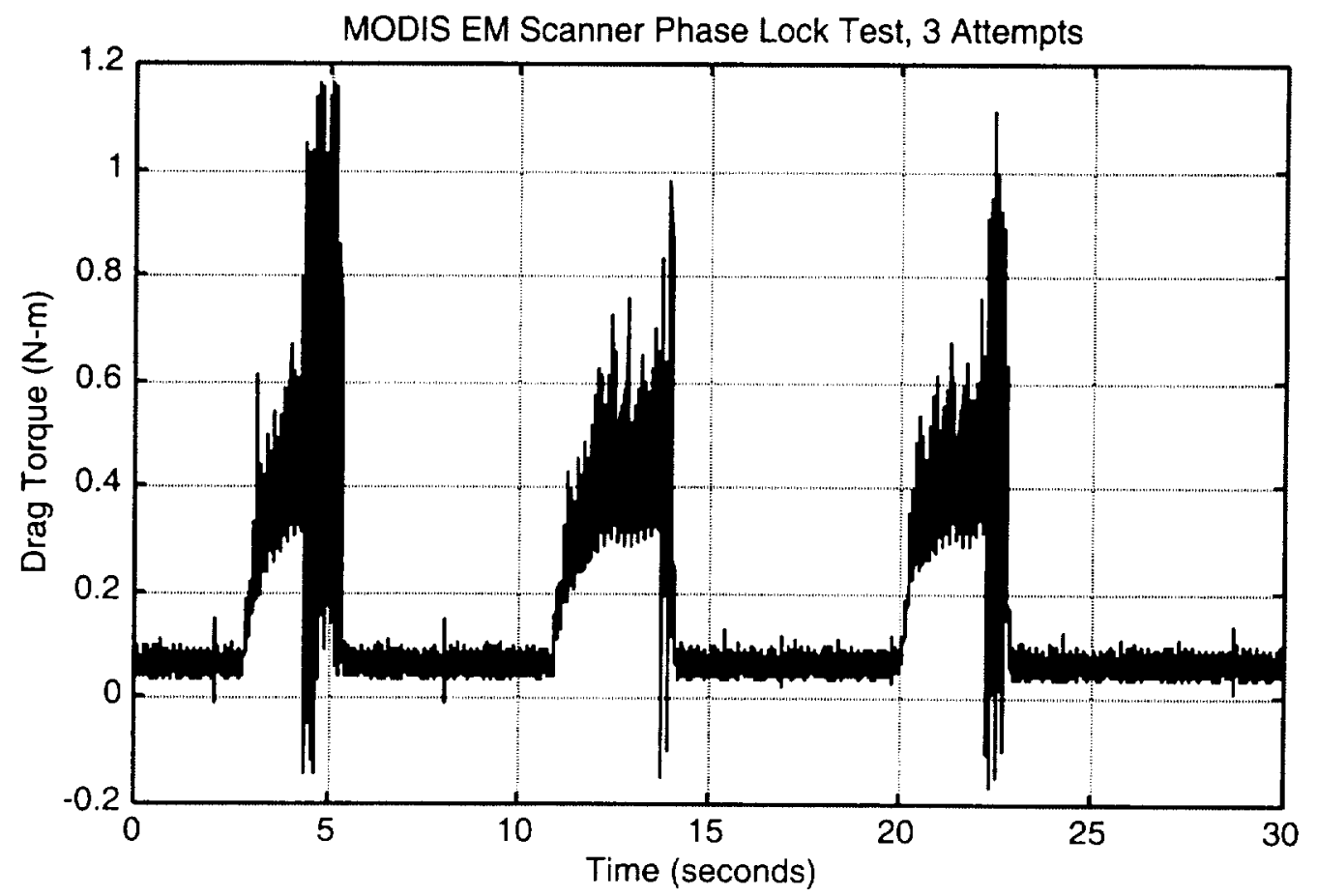

Figure 17 - MODIS EM Scanner Phase Lock Test 2. 


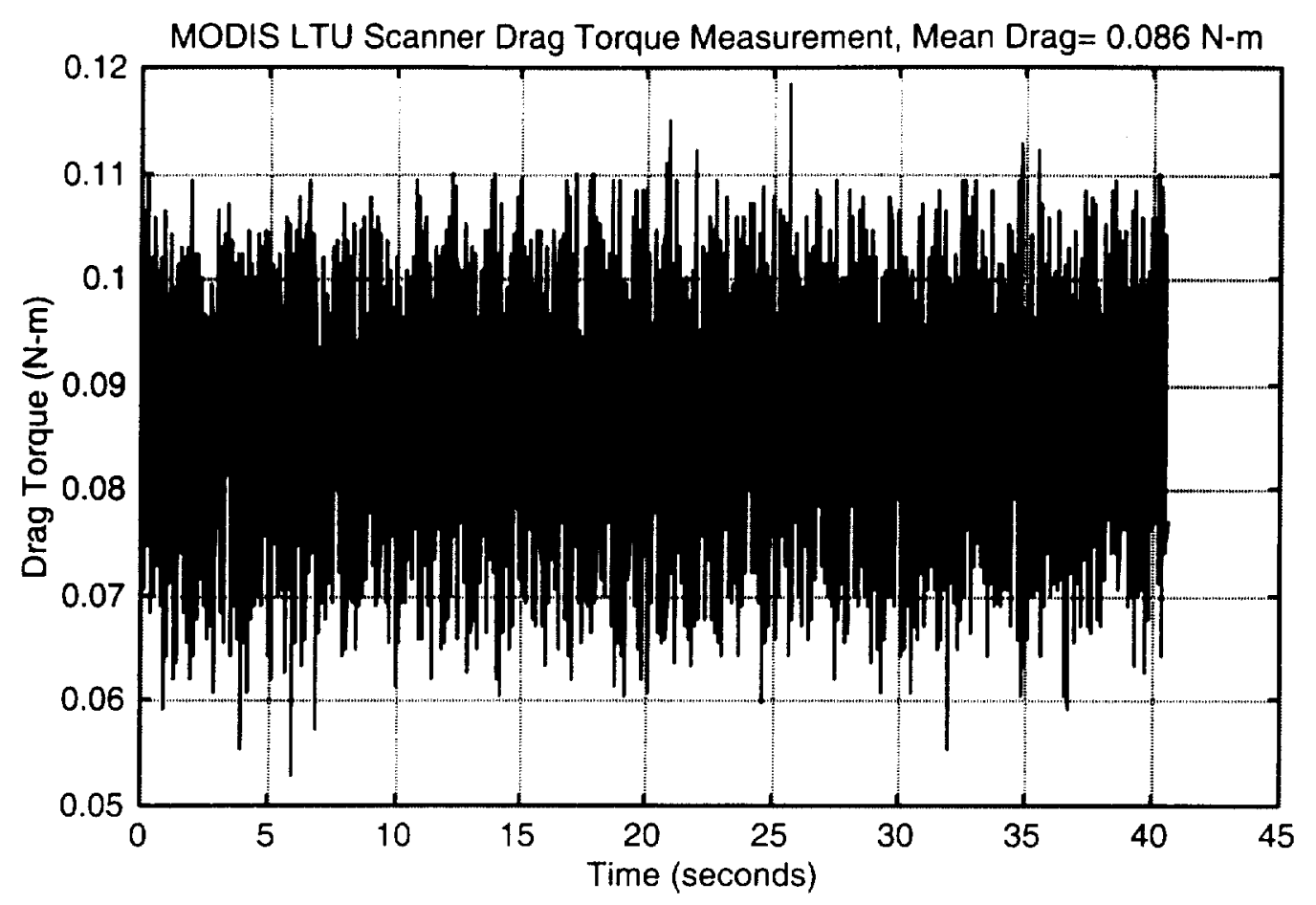

Figure 18 - MODIS LTU Scanner Steady State Drag Torque. 


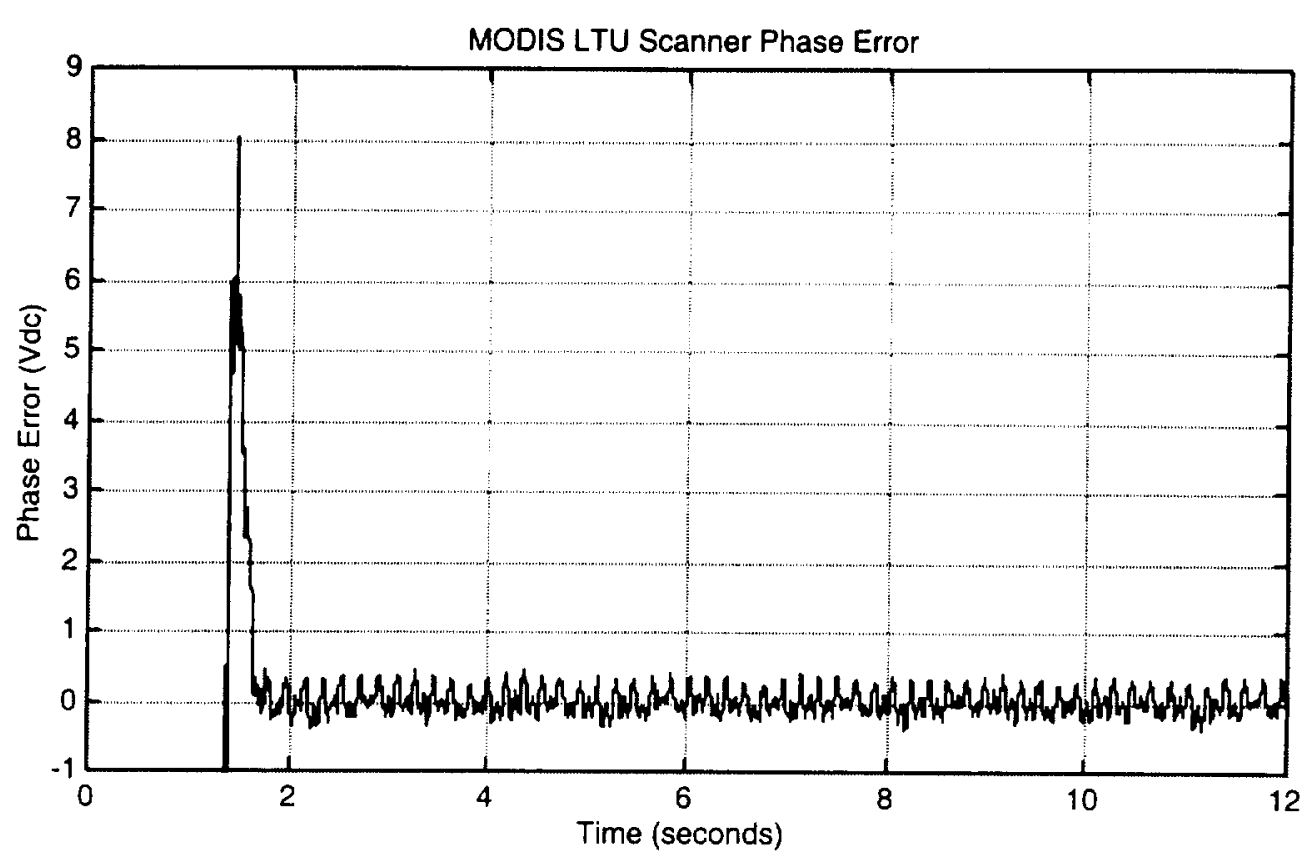

Figure 19 - MODIS LTU Scanner Phase Error.

\section{CONCLUSIONS}

The steady state drag torques measured on the MODIS EM and LTU scanner units were about $.067 \mathrm{~N}-\mathrm{m}$ (9.4 oz-in) and .087 N-m (12.2 oz-in) respectively indicating a beginning-of-life and a end-of-life torque margin of greater than 20 . The more important parameter of phase lock margin for both units was a healthy 200 percent. Because of the design similarities between the EM and LTU scanner units and the PFM and FM-1 MODIS scanners, it was concluded that the PFM and FM-1 unit MODIS scanners had sufficient margin for a five-year mission life on the EOS-AM (Terra) and EOS-PM (Aqua) programs respectively.

\section{LESSONS LEARNED}

As a worn slip ring was the cause of heater loss in the accelerated test station, it was shown that the test equipment must be more robust than the hardware being tested. Also, in the presence of gravity, considerations for the orientation of test samples should be given. Where feasible, rotation of the samples should be performed to counter the effects of gravity. The labyrinth seal should match that of the flight configuration. And lastly, when testing mechanical systems consider the frequency of the test apparatus. In this test it was noted that jitter, seen during life testing, was likely due to the cantilevered test arm resonating or coupling with the rotational speed of the bearings.

\section{ACKNOWLEDGEMENTS}

J. Uber, S. Cicchelli, and M. Roberto, NASA Goddard Space Flight Center.

A. DeForrest, Raytheon Systems Company, Santa Barbara Remote Sensing.

L. Alegre, S. Natvipada, D. Owens, T. Phan, P. Tokeshi and H. Tsui, Moog SMD.

N. St. Pierre and M. LaRochelle, Nye Lubricants 


\section{REFERENCES}

1. Brian J. Dietz, Steven G. VanDyk and Roamer E. Predmore, "Earth Scanner Bearing Accelerated Life Test", 34 ${ }^{\text {th }}$ Aerospace Mechanisms Symposium, May 2000, pp 303-316. 